\title{
ОЦЕНКА УГЛЕВОДНОГО ОБМЕНА НА ФОНЕ ТЕРАПИИ ГЛЮКОКОРТИКОИДАМИ (ОПИСАНИЕ КЛИНИЧЕСКОГО СЛУЧАЯ)
}

\author{
Шрёдер Е.В., Витебская А.В.
}

ФГАОУ ВО «Первый Московский государственный медицинский университет имени И. М. Сеченова» Минздрава России (Сеченовский Университет), Москва

Глюкокортикоиды (ГК) широко применяются в терапии хронических воспалительных и аутоиммунных заболеваний. Одной из проблем терапии ГК является развитие метаболических осложнений.

ЦЕЛЬ: описание клинического случая, демонстрирующего развитие нарушения углеводного обмена на фоне приема ГК.

КЛИНИЧЕСКИЙ СЛУЧАЙ: Пациентка 12 лет, наблюдается в детском эндокринологическом отделении Университетской детской клинической больницы в течение 1 года.

Девочка с нормальными массо-ростовыми показателями при рождении, наблюдалась по поводу избыточной массы тела с раннего возраста. Наследственный анамнез отягощен по ожирению.

В 9 лет манифестация ювенильной системной склеродермии (ЮССД).

При обследовании в 10 лет 9 мес: рост 144 см (SDS роста +0,3), вес 49 кг (SDS ИМТ +1,6), половое развитие по Таннеру 2-3 (B2 Р3), нарушений углеводного обмена и инсулинорезистентности не выявлено (уровень инсулина натощак 7,1 мкME/мл (HOMA=1,26, Caro=0,56), максимальный уровень инсулина на фоне перорального глюкозотолерантного теста (ПГТТ) 131,0 мкМЕ/мл.

По поводу ЮССД была назначена терапия ГК (метипред в стартовой дозе 16 мг/сут (0,4 мг/кг/сут по преднизолону).

Через месяц от начала приема ГК (11 лет 10 мес): рост 144 см (SDS роста +0,21), вес 49 кг (SDS ИMT +1,94), перераспределение подкожножировой клетчатки по кушингоидному типу, повышение аппетита, выраженная эмоциональная лабильность. Диету с ограничением легкоусвояемых углеводов соблюдала, двигательная активность - 3 раза в неделю по 60 минут подвижные игры. По результатам обследования показатели гликемии в пределах нормы, появилась базальная инсулинорезистентность (HOMA=4,21, Caro=0,17), максимальный уровень инсулина в ходе ОГТТ 67,4 мкМЕ/мл.

В связи сулучшением клинической картины ЮССД начато постепенное снижение дозы ГК. Через 5 мес от начала приема ГК (11 лет 4 мес) на фоне приема 8 мг/сут (0,17 мг/кг/сут по преднизолону): рост 145 см (SDS роста: -0,02), вес 58 кг (SDS ИMT: +2,6), выраженное перераспределение подкожножировой клетчатки по кушингоидному типу, явления матронизма, гипертрихоз, половое развитие по Таннеру 2-3 (В2 Р3). Отмечено увеличение массы тела прогрессирующего характера (+9 кг за 5 мес, снижение темпов роста 1 см/5 мес), появились боли и усталость в спине, повышенный аппетит. Диету с ограничением легкоусвояемых углеводов и режим питания не соблюдает, двигательная активность достаточная. По результатам обследования показатели гликемии в норме, выявлена выраженная гиперинсулинемическая инсулинорезистентность (уровень инсулина натощак 11,1 мкME/мл (Matsuda=2,2, HOMA=1,83, Caro=0,33), в ходе ПГТТ подъем более 300 мкME/мл). Продолжено снижение дозы ГК.

Через 1 год от начала приема ГК (12 лет 0 мес): рост 147 см (SDS роста -0,26), вес 56,5 кг (SDS ИMT 2,3). Около полугода в весе стабильна, скорость роста 3,4 cм/год (SDS скорости роста -4,3)). Отмечен повышенный аппетит, диету периодически нарушает, двигательная активность достаточная. При поступлении находилась на низкой дозе ГК (метипред 4 мг/сут, по преднизолону 0,09 мг/кг/сут). Отмечена прогрессия полового развития, стадия по Таннеру (B3 Р4). По результатам ПГТТ выявлено нарушение толерантности к глюкозе (гликемия через 2 ч 8,2 ммоль/л), гиперинсулинемия (уровень инсулина натощак 13,1 мкME/мл (HOMA=2.27, Caro=0,3), максимальный подъем в ходе ОГТТ более 300 мкМЕ/мл). Учитывая предстоящую отмену ГК, нормогликемию в течение суток, рекомендовано строгое соблюдение ограничительной диеты и повышение физической активности.

ВЫВОДЫ: данный клинический случай демонстрирует побочные эффекты терапии ГК в виде развития медикаментозного синдрома Иценко-Кушинга. Прогрессирование ожирения и инсулинорезистентности, несмотря на снижение дозы ГК, позволяет говорить о роли соблюдения диеты в формировании осложнений терапии ГК.

КЛЮЧЕВЫЕ СЛОВА: медикаментозный синдром Иценко-Кушинга; экзогенный гиперкортицизм; инсулинорезистентность; нарушение толерантности к глюкозе. 